\title{
The structural basis of MRI bone erosions: an assessment by microCT
}

\author{
Andreas Albrecht, ${ }^{1}$ Stephanie Finzel, ${ }^{1}$ Matthias Englbrecht, ${ }^{1}$ Jürgen Rech, ${ }^{1}$ \\ Axel Hueber, ${ }^{1}$ Philipp Schlechtweg, ${ }^{2}$ Michael Uder, ${ }^{2}$ Georg Schett ${ }^{1}$
}

Handling editor Tore K Kvien

- An additional supplementary table is published online only. To view this file please visit the journal online (http://dx.doi. org/10.1136/annrheumdis2012-201982)

1 Department of Internal Medicine 3, University of Erlangen-Nuremberg, Erlangen, Germany

${ }^{2}$ Institute of Radiology, University of ErlangenNuremberg, Erlangen, Germany

\section{Correspondence to} Professor Georg Schett, Department of Internal Medicine 3, Rheumatology and Immunology; University of Erlangen-Nuremberg; Krankenhausstrasse 12 Erlangen D-91054, Germany; georg.schett@uk-erlangen.de

Accepted 14 August 2012 Published Online First 19 September 2012

\section{ABSTRACT}

Objective To determine whether erosions appearing in $\mathrm{MRI}$ in patients with rheumatoid arthritis (RA) represent true erosions.

Methods 50 RA patients received $1.5 \mathrm{~T} \mathrm{MRI}$ and microCT ( $\mu \mathrm{CT}$ ) of the dominant hand. Erosion counts were assessed in coronal T1 weighted MRI sections and in coronal as well as axial $\mu C T$ sections of the metacarpophalangeal (MCP) joints II-IV. Extent of erosions was assessed by RA MRI Score (RAMRIS) erosion score (MRI) and by three-dimensional assessment of erosion volume ( $\mu \mathrm{CT})$.

Results 111 of the 600 evaluated joint regions showed erosions in the MRI and 137 in the $\mu \mathrm{CT}$. In only 28 regions false negative lesions ( $\mu \mathrm{CT}$ positive, MRI negative) were found, all of which were very small lesions with a volume of less than $10 \mathrm{~mm}^{3}$. Only two results were false-positive ( $\mu \mathrm{CT}$ negative, MRI positive). RAMRIS erosion scores were strongly correlated to erosion volumes in the $\mu \mathrm{CT}$ (Pearson's $r=0.514$, $p<0.001)$. Mean RAMRIS erosion scores were below 1 with erosion volumes up to $1.5 \mathrm{~mm}^{3}$, below 2 with erosion volumes up to $20 \mathrm{~mm}^{3}$ and over 2 with volumes of more than $20 \mathrm{~mm}^{3}$.

Discussion MRI erosions are generally based on true cortical breaks as shown by $\mu \mathrm{CT}$. MRI is sensitive to detect bone erosions and only very small lesions escape detection. Moreover, RAMRIS erosion scores are closely linked to the absolute size of bone erosions in the $\mu \mathrm{CT}$.

\section{INTRODUCTION}

Rheumatoid arthritis (RA) is a chronic inflammatory disease, which is characterised by inflammation of synovial membrane leading to bone destruction. ${ }^{1}$ Already in its early stages, RA is accompanied by changes in the periarticular bone architecture. $^{2}$ In order to detect such lesions, imaging techniques like MRI, CT and conventional radiography are of particular importance. ${ }^{3-5}$ Next to inflammatory lesions, like synovitis and osteitis ('bone marrow oedema'), bone erosions are pathognomonic findings in the imaging of patients with RA. ${ }^{6-9}$ Accurate detection of bone erosion is of particular importance, as these lesions reflect irreversible damage to the affected joints and closely relate to functional impairment. ${ }^{10-12}$ Prevention of bone erosion is therefore of seminal importance for the treatment of RA.

Optimisation of imaging measures is an important strategy to improve detection and monitoring of bone damage in RA. Conventional radiography is the best-validated imaging technique to assess bone damage so far, but there are limitations due to the two-dimensional character of radiographs. ${ }^{5}$ In consequence, MRI and CT gain importance for the assessment of bone erosions in RA. ${ }^{4}{ }^{13}$ CT is often considered as the gold standard for detection of bone erosion as it combines the advantages of radiography for the assessment of bone structure with the strengths of tomographic techniques such as high degree of resolution and the threedimensional character. ${ }^{3}$ However, in contrast to MRI CT imaging lacks the possibility to simultaneously assess the inflammatory changes of RA such as synovitis and osteitis. ${ }^{14}$

Therefore, it is important to exactly define the accuracy of MRI to detect bone erosion. Direct comparison between conventional CT scanning and MRI gave stimulating results suggesting that specificity and sensitivity of MRI in detecting bone erosions is high. ${ }^{3}$ Recently, high-resolution CT scanners have been developed for exactly defining the bone architecture so that this method can be used to assess periarticular bone in RA. ${ }^{2}$

Based on our recent experience with high resolution micro CT $(\mu \mathrm{CT})$ scanning we were interested to validate the nature of MRI bone erosions. $\mu \mathrm{CT}$ allows measuring the volume of individual erosions indirectly and thus exactly defines the extent of structural damage. We were thus interested to validate the specificity and sensitivity of $\mathrm{MRI}$ in detecting bone erosions in RA by the $\mu \mathrm{CT}$.

\section{METHODS}

\section{Patients}

Fifty patients with RA (31 women and 19 men) from the Rheumatology Outpatient Clinic of the University Clinic of Erlangen were included. All patients fulfilled the old and new American College of Rheumatology classification criteria for RA. To estimate the disease activity, disease activity score (DAS 28) was recorded. All patients received MRI and $\mu \mathrm{CT}$ scanning of the dominantly affected hand. The study was performed in accordance with the Declaration of Helsinki. Approval from the local ethics committee and the national radiation safety agency (Bundesamt für Strahlenschutz) concerning informed consent was obtained for the study.

\section{MicroCT}

All patients received $\mu \mathrm{CT}$ of the metacarpophalangeal (MCP) joint region of the dominantly affected hand using an XtremeCT scanner (SCANCO 
Medical AG, Brüttisellen, Switzerland). Scans were performed at $82 \times 82 \times 82 \mu \mathrm{m}$ voxel size (as previously described by Stach et $a l^{2}$ with a spatial resolution of more than 4.8 line pairs (lp) $/ \mathrm{mm}$ at $10 \%$ modulation transfer function, which means that one line pair corresponds to about $200 \mu \mathrm{m}$. We use the same custom made holder for all assessments. The hand was positioned in an outstretched position and padded. The scan region is maximum 80 slices distal and 242 slices proximal to the upper margin of the third metacarpal head. That is, 322 slices in total and the scan time is between 5.6 and $8.4 \mathrm{~min}$. MCP joints of the second, third and fourth digit were assessed for the presence and size of bone erosions, which were defined as a juxta-articular break within the cortical shell. Five patients had to be excluded from further evaluation because of movement artefacts yielding an overall number of 50 patients for further analyses.

\section{MRI}

For the MRI scans we used a $1.5 \mathrm{~T}$ MAGNETOM Avanto system (Siemens, Erlangen, Germany). The examined hand was positioned in an overhead position using a high resolution body coil (32 channels). For the T1 weighted coronal sequences, which we used for determining RA MRI Score (RAMRIS) erosion score, the resolution size was $0.7 \times 0.5 \times 2.5 \mathrm{~mm}$ voxel with a matrix of $70 \times 448$ and a field of view (FOV) of $220 \mathrm{~mm}$. The echo time was $13 \mathrm{~ms}$, the repetition time was $497 \mathrm{~ms}$. For defining erosions in the MRI we used the definition of the OMERACT-Group: an erosion is a sharply marginated bone lesion with correct juxta-articular localisation and typical signal characteristics, which is visible in two planes with a cortical break seen in at least one plane. ${ }^{15}$

\section{Imaging data analysis}

For image analysis, the ulnar and radial sides at both the metacarpal heads II, III and IV as well as the respective phalangeal bases II, III and IV were analysed for bone erosions in the MRI and $\mu C T$ scans (totally 12 regions, 4 per joint). For MRI erosions we evaluated images semi-quantitatively based on the work of the OMERACT-Group for evaluation of bone erosions according to the RAMRIS erosion score. ${ }^{16-18}$ We modified this method in the way that we assessed the joint as a whole and separately scored the ulnar and radial parts of each joint. Scores between 0 and 10 for the radial or ulnar side of the joint can be reached depending on the degree of bone erosion in coronal sections $(0=0 \%, 1=1-$ $10 \%$, etc, up to $10=91-100 \%)$. As this score refers only to joint regions by contrast to the 'classical' RAMRIS erosion score, we called it 'modified' RAMRIS erosion score. For evaluation of $\mu$ CT erosions we exactly assessed the three-dimensional size of the dominant erosion in each of the aforementioned regions by using coronal and axial sections. We thereby received the data for the maximal transversal width $\left(t_{\mathrm{w}}\right)$, coronal width $\left(\mathrm{c}_{\mathrm{w}}\right)$ and coronal depth $\left(c_{d}\right)$. As most of the erosions geometrically approximate a half ellipsoid, we used the half ellipsoid shape to calculate erosion volume. If erosions are taken as half ellipsoid, 1/2 $t_{w}, 1 / 2 c_{w}$ and $\mathrm{c}_{\mathrm{d}}$ are the related radii and the erosion volume can be calculated according to the formula:

$$
\mathrm{V}_{\text {erosion }}=\frac{\pi \times \mathrm{t}_{\mathrm{w}} \times \mathrm{c}_{\mathrm{w}} \times \mathrm{c}_{\mathrm{d}}}{6}
$$

Reading of the images was done by two independent readers for the $\mu \mathrm{CT}$ (AA and SF; volume assessment was done by AA) and for the MRI (AA and SF), who were unaware of the identity, clinical data and treatment modalities of the patients.
Table 1 Evaluation of the 600 examined joint regions for the prevalence of erosions

\begin{tabular}{lccl}
\hline Rater $\mathbf{1}$ (rater 2) & $\boldsymbol{\mu C T}$ positive & $\boldsymbol{\mu C T}$ negative & Total \\
\hline MRI positive & $109(105)$ & $2(6)$ & $111(111)$ \\
MRI negative & $28(32)$ & $461(457)$ & $489(489)$ \\
Total & $137(137)$ & $463(463)$ & $600(600)$ \\
\hline
\end{tabular}

'Positive' indicates that at least one erosion was found in the respective joint region. Results with a positive finding in the $\mu \mathrm{CT}$ and negative finding in the MRI are considered false-negative, those with a negative finding in the $\mu$-CT and a positive finding in the MRI are considered false-positive. With $\mu \mathrm{CT}$ as gold standard for detecting erosions the average values for MRI sensitivity and specificity are $x_{\text {sens }}=0.79$ and $x_{\text {spec }}=1.0$. The respective negative and positive predictive values are $\mathrm{x}_{\mathrm{NPV}}=0.94$ and $\mathrm{x}_{\mathrm{PPV}}=0.97$.

\section{Statistical analysis}

MRI sensitivity, specificity, positive and negative predictive values for detection of erosions were calculated supposing that $\mu \mathrm{CT}$ is the gold-standard for detection of erosions. We also compared mean numbers of both $\mu \mathrm{CT}$ and MRI and the mean difference of erosion counts between both modalities separately for each joint region. To demonstrate significant differences between both modalities t-test for paired samples was used for the respective joint regions. The modified RAMRIS erosion scores (based on separate assessment of ulnar and radial sides) and standard RAMRIS erosion scores (based on assessment of whole joints) were related to the volumes of the erosions of radial and ulnar sides as well as the added volumes of $\mu \mathrm{CT}$ scans.

To investigate the relationship between RAMRIS erosion scores and the corresponding volumes Bravais-Pearson correlation was calculated. We also performed subgroup analysis based on the severity of MRI erosions (1: RAMRIS $=0$; 2: RAMRIS $=1-2$; 3 : RAMRIS $\geq 3$ ) and compared these subgroups with respect to erosion volume by using the Mann-Whitney-U-Test. Furthermore, we generated five subgroups reflecting the size of $\mu$ CTerosions (1: $0-0.49 \mathrm{~mm}^{3}, 2: 0.5-1.49 \mathrm{~mm}^{3}, 3: 1.5-4.9 \mathrm{~mm}^{3}, 4: 5-19.9 \mathrm{~mm}^{3}$, $5: \geq 20 \mathrm{~mm}^{3}$ ) and RAMRIS erosion scores in these five subgroups. To investigate significant differences Mann-Whitney-U-test was used.

To model the dependent variable (ie, the added radial and ulnar erosion volume at each evaluated phalangeal base or metacarpal head) by the corresponding RAMRIS we used a generalised mixed linear model with age, sex, disease duration and disease activity as covariates. Additionally, we included a random intercept and a compound symmetry covariance structure. The corresponding results are expressed as robust regression coefficients, which were favoured in case of any variable in the model eventually not meeting the methodological requirements.

Inter class correlations (ICCs), per cent close agreements (PCA) and exact agreements were obtained for MRI and CT erosions. PCA and per cent exact agreement (PEA) are conservatively stated for the lowest ICC in each category. PCA was defined as the two readers rating within $\pm 3^{\circ}$ of the measurement scale according to Hellebrandt and colleagues. ${ }^{19}$ For all analyses IBM SPSS statistics V.19.0 was used. A p value of less than 0.05 was considered as statistically significant.

\section{RESULTS}

High correlation of erosion numbers in the MRI and $\boldsymbol{\mu C T}$ scans A total number of $50 \mathrm{RA}$ patients were investigated with a mean $\pm S D$ age of $54.4 \pm 14.4$ years, mean \pm SD disease duration of $31.56 \pm 42.77$ years and a mean \pm SD disease activity according to the DAS28 score of $4.00 \pm 1.74$ units. Both raters found 
erosions in 137 of the 600 evaluated joint regions erosions in the $\mu \mathrm{CT}$, whereas erosions in 111 regions were found in the MRI. Of them, 28 (rater one, 32 with rater two) showed discordant results with negative MRI scans but detection of a cortical break in the $\mu \mathrm{CT}$ (table 1). Positive MRI scans but negative $\mu \mathrm{CT}$ scans were rare and only found in two (rater one, six with rater two) different joint regions. The inter-rater reliability of erosions in the $\mu \mathrm{CT}$ scans was higher (Pearson's $r=0.975 p<0.01$ ) than for those in the MRI scans (Pearson's $\mathrm{r}=0.931 \mathrm{p}<0.01)$. ICC ranges, PCAs and PEAs for the RAMRIS erosion scores in the metacarpal heads were 0.949-1.00, 100\% and $90 \%$, respectively, for the phalangeal bases they were 0.807-1.00, 100\% and 94\%, respectively. ICC ranges, PCAs and PEAs for MRI erosion counts in the metacarpal heads were $0.878-1.00,100 \%$ and $92 \%$, respectively, whereas they were $0.686-1.00,100 \%$ and $92 \%$ in the phalangeal bases. ICC ranges, PCAs and PEAs for the erosion counts in the micro-CT were $0.936-1.00,100 \%$ and $96 \%$, respectively, for the metacarpal heads and $0.948-1.00,100 \%$ and $98 \%$ for the phalangeal bases.
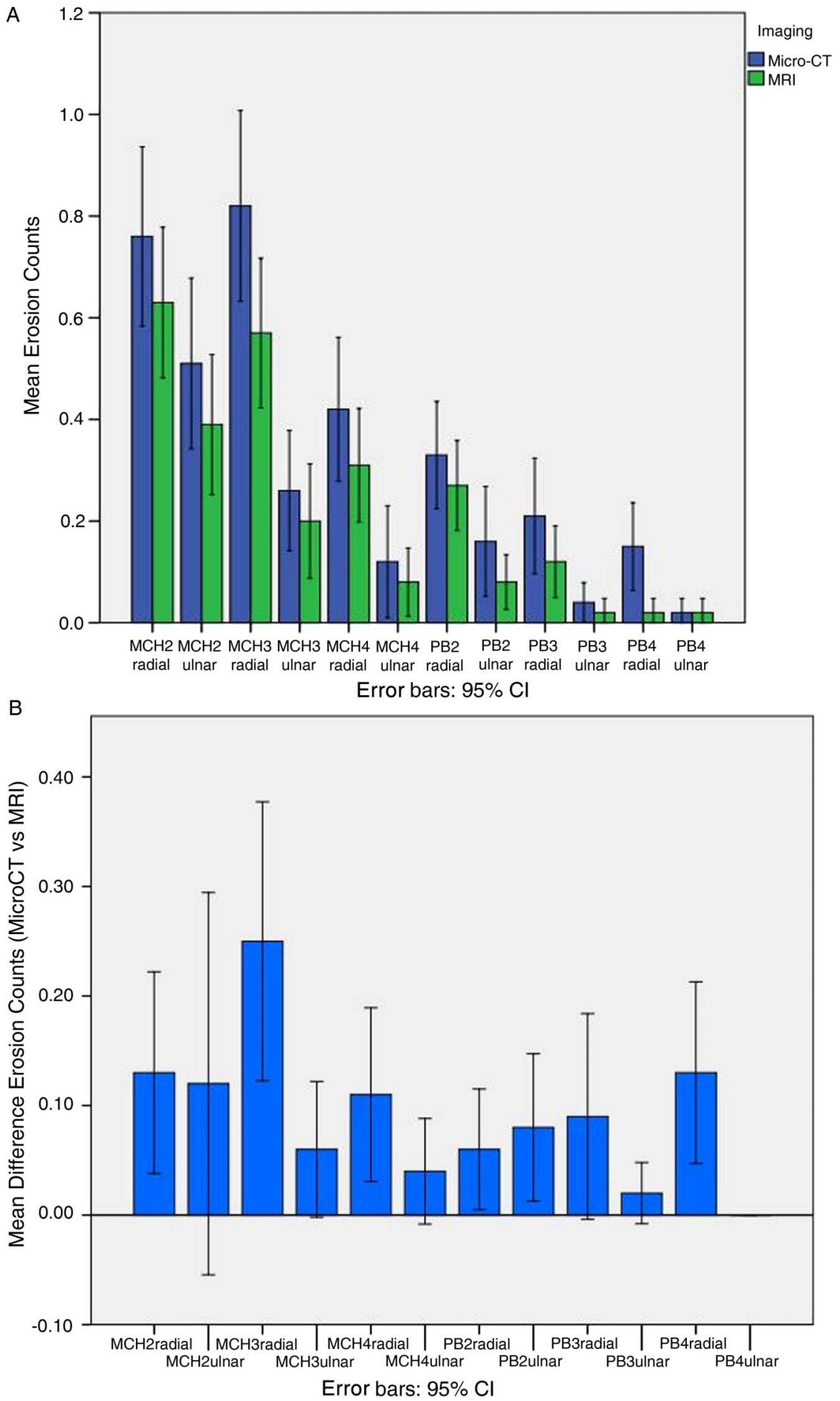

Figure 1 (A) Comparative analysis of mean erosion counts as assessed by the two different modalities $\mu$-CT (blue) and MRI (green). (B) Mean Difference of erosion counts (difference between the number of $\mu$-CT and MRI erosions) for each of the joint regions. This figure is only reproduced in colour in the online version. 

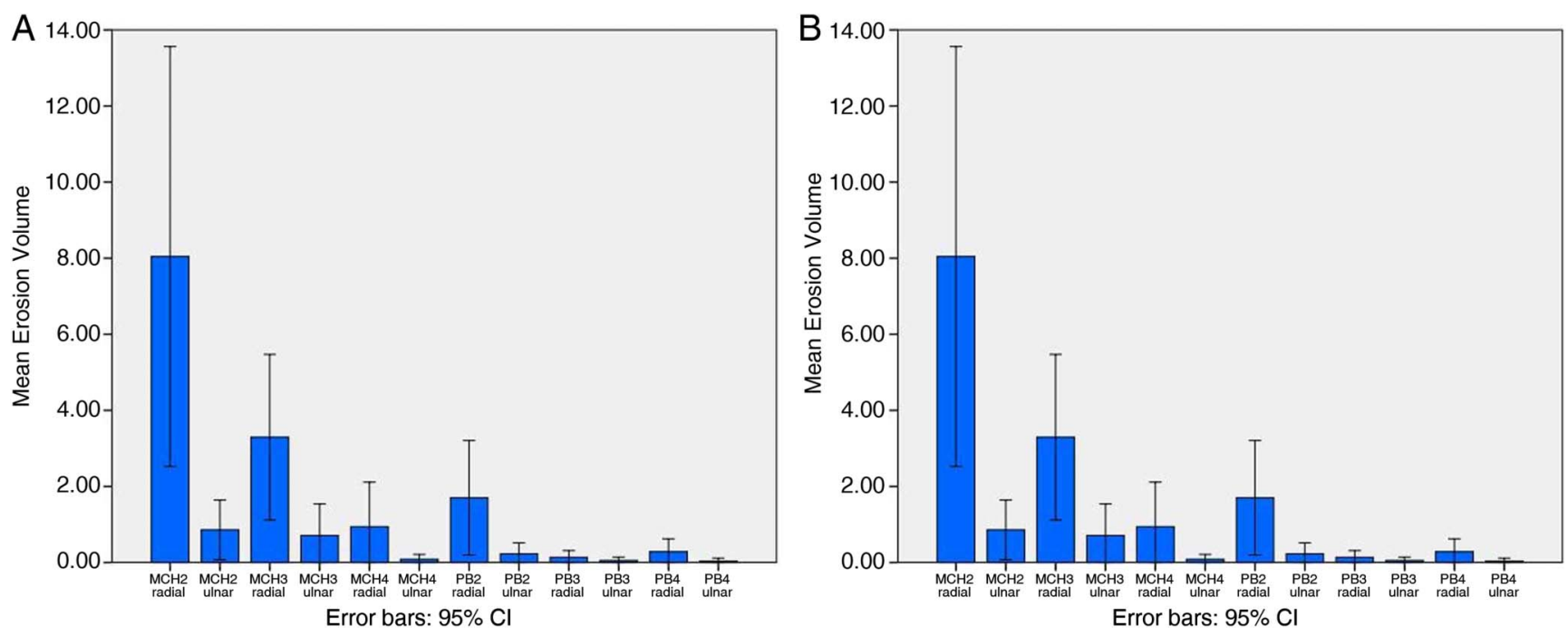

Figure 2 (A) Mean Erosion Volume of the examined joint regions for the $\mu$-CT scans; (B) Mean modified RAMRIS erosion score for the MRI scans. This figure is only reproduced in colour in the online version.

\section{Similar distribution of bone erosions in the MRI and $\mu \mathrm{CT}$ scans}

When analysing the distribution pattern of bone erosions among the different joint regions we found strongly homogenous results in the MRI and the $\mu \mathrm{CT}$ (figure 1A). A significant difference in the number of erosions could be only found in the radial region of the fourth phalangeal base $(p=0.002)$. When calculating the mean difference of MRI and $\mu \mathrm{CT}$ erosions counts separately for each examined joint region, we found that $\mu \mathrm{CT}$ picks up slightly more erosion at the radial region of the MCP heads (figure 1B). Both imaging techniques showed preferential affection of the metacarpal heads as compared with the phalangeal bases, as well as preferential affection of the second and third as compared with the fourth MCP joint. Moreover, the most several affected sides were the radial sides of the metacarpal heads II and III with high consistency among both imaging techniques. When analysing the severity of erosive changes with respect to anatomical distribution, a very similar picture occurs: figure 2 shows the volume of erosions per joint region determined by $\mu \mathrm{CT}$ (figure $2 \mathrm{~A}$ ) and the mean modified RAMRIS MRI erosion score per joint region (figure $2 \mathrm{~B}$ ). Both MRI and $\mu \mathrm{CT}$ showed higher severity of erosive lesions in the metacarpal heads, the second and third digit as well as the radial sides of the joints as compared with the phalangeal bases, the fourth digit and the ulnar sides, respectively.

\section{Correlation of bone erosions in the MRI and $\mu \mathrm{CT}$}

Direct comparison of erosion counts in both imaging modalities showed the aforementioned significantly higher number of bone erosions detected by $\mu \mathrm{CT}$ than by MRI, suggesting that some bone erosion may escape detection by MRI (figure 3). This difference is most evident at the radial side of metacarpal head III. When correlating the extent of bone erosion in the MRI (X-axis) with the absolute size of lesions in the $\mu \mathrm{CT}$ (Y-axis); however, strong correlations were found $(\mathrm{r}=0.514$, $\mathrm{p}<0.001$ ) (figure 3). Correlation between the extent of MRI and $\mu C T$ erosions was higher when localised at the radial side $(\mathrm{r}=0.492, \mathrm{p}<0.001)$ than at the ulnar side $(\mathrm{r}=0.434 ; \mathrm{p}<0.001)$ (figure 3 ). The few bone erosions that could not be depicted by MRI were very small lesions with less than $10 \mathrm{~mm}^{3}$ in volume. On the other hand, we also found a subset of lesions, which showed very small erosion volumes and in few cases even no sign of a cortical break in the $\mu \mathrm{CT}$, which showed rather substantial changes in the MRI. In particular, such lesions were found at the radial sides of the MCP joints (figure 3). It well may be that such lesions, which are based on high water content reflecting inflammation in close connection to the cortical bone may reflect pre-erosions (in case of absent $\mu \mathrm{CT}$ changes) or very early lesions (in case of minimal $\mu \mathrm{CT}$ changes). Longitudinal studies are necessary to clarify this issue.

\section{Erosion volume in the $\mu \mathrm{CT}$ and relation to RAMRIS erosion scoring}

We next built subgroups according to the RAMRIS erosion scoring with regions showing no (RAMRIS=0), mild-to-moderate (RAMRIS 1-2) or severe (RAMRIS $\geq 3$ ) lesions. When assessing the mean erosion volume of these subgroups, we could clearly show that negative results in the erosion RAMRIS score indeed lacks signs for bone erosion in the $\mu \mathrm{CT}$ (figure 4). Moreover, there was a clear and significant difference in the size of erosions between the groups showing mild-to-moderate (RAMRIS 1-2) or severe (RAMRIS $\geq 3$ ) MRI lesions (eg, subgroup 2 vs subgroup 3 ( $U=113$; $Z=-9.71 ; p<0.001))$. Thus, RAMRIS score can estimate the extent of erosions with a high accuracy. In addition, we made the reverse testing by building subgroups based on the erosion volume in the $\mu \mathrm{CT}$ and assessing the respective RAMRIS erosion scores for each of these subgroups RAMRIS erosion scores (figure 5). Interestingly we could find a strictly 'dose-dependent' relation between the absolute erosion size measured by $\mu \mathrm{CT}$ and the RAMRIS erosion score underlining the value of RAMRIS scoring for assessing the extent of erosive lesions (eg, subgroup 1 vs 4 $(\mathrm{U}=213 ; \mathrm{Z}=-10.31 ; \mathrm{p}<0.001)$ or subgroup 2 vs $5(\mathrm{U}=39.5 ; \mathrm{Z}=$ $-5.13 ; p<0.001)$ ). The data also showed that only very small lesions with erosion volumes of less than $0.5 \mathrm{~mm}^{3}$ show virtually negative RAMRIS scores, whereas significant changes can be already seen with small bone lesions with erosion volumes between 0.5 and $1.5 \mathrm{~mm}^{3}$.

Furthermore, we confirmed the strong relationship between the total RAMRIS and the corresponding total erosion volume by generalised mixed linear model, which controls for withinpatient correlation. Thus, RAMRIS is independently and positively associated with the erosion volume measured by $\mu \mathrm{CT}$ 

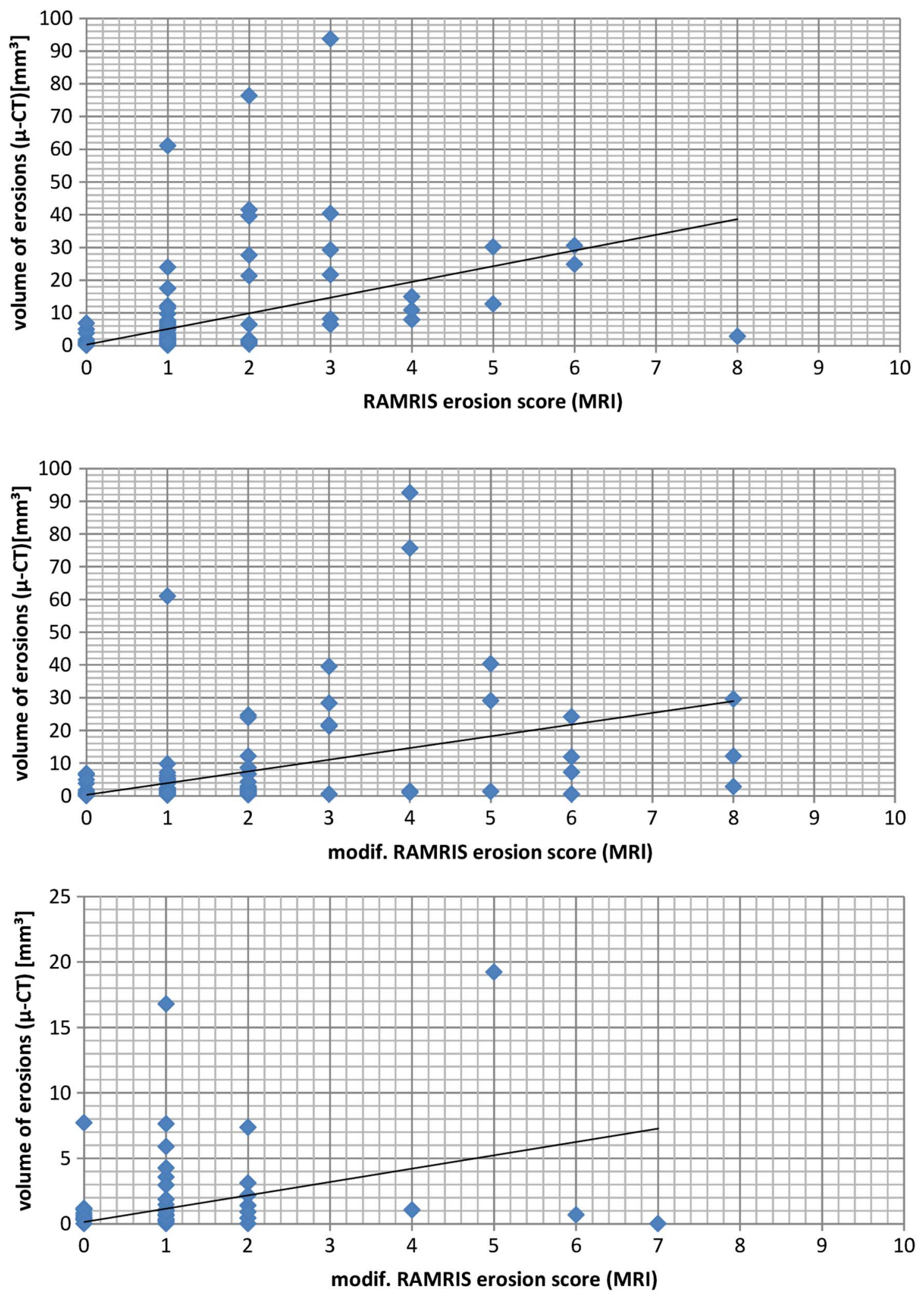

Figure 3 (A) Correlation between the added erosion volumes (top: sum of marker erosion of ulnar and radial sides; middle: radial; bottom: ulnar) and $(B)$ the RAMRIS erosion score of the respective joint regions $(r=0.514, p<0.001)$. This figure is only reproduced in colour in the online version.

$(\mathrm{p}<0.001)$ after controlling for the influence of age, sex, disease duration and disease activity (see online supplementary table S1). This implies that patients with higher RAMRIS scores also show larger erosions in $\mu \mathrm{CT}$ independent from demographic characteristics or disease activity. This effect was also to be found when replacing the RAMRIS by the RAMRIS categories shown in figure 4. RAMRIS categories 1 (ie, RAMRIS 0) and 2 (ie, RAMRIS 1 to 2) showed significantly smaller erosion volume when compared with RAMRIS category 3 (ie, RAMRIS of at least 3 ) with $p<0.001$ and $p=0.009$, respectively. 


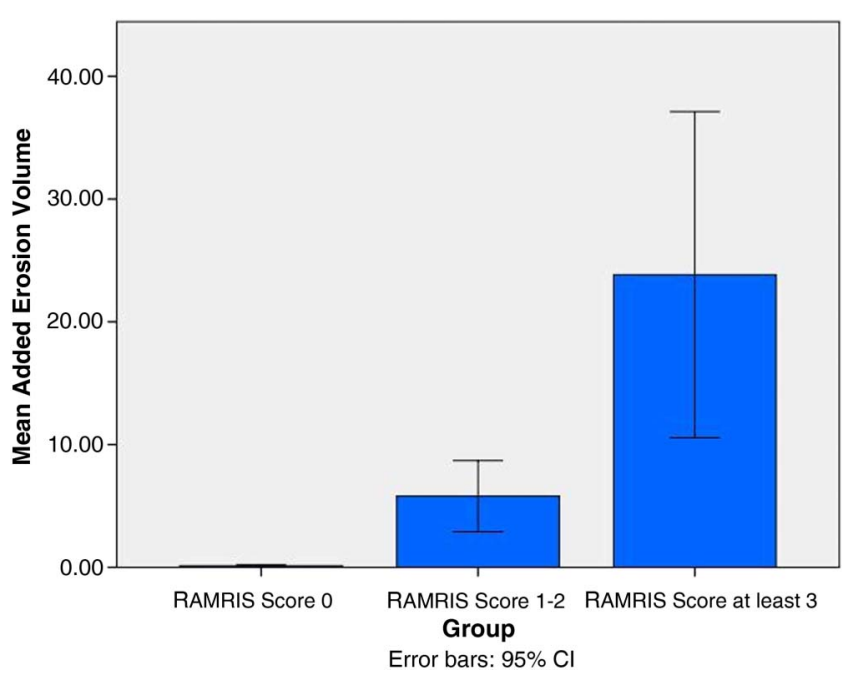

Figure 4 Mean added erosion volume (sum of marker erosion of the ulnar and radial side) for the respective RAMRIS Erosion Score groups. This figure is only reproduced in colour in the online version.

\section{DISCUSSION}

Herein we show, that standard MRI scanning and scoring of erosions according to the RAMRIS method shows high accuracy in detecting bone erosions. We validated MRI by direct quantitative assessment of the size of bone erosions by $\mu \mathrm{CT}$, which is to date the most sensitive method to depict even minimal cortical bone changes in humans. ${ }^{2}$ The high accuracy of standard MRI in detecting bone erosions is important as MRI is widely used to quantify the extent of inflammation in $\mathrm{RA}$ and to detect structural damage. ${ }^{20}$

MRI is generally not the preferred imaging technique to analyse bone structure but offers excellent opportunities to detect inflammatory tissue in arthritis including the juxtaarticular bone marrow. Therefore MRI, aside high-resolution ultrasound, is the technique of choice to quantify the structural burden of arthritis. ${ }^{4} 2122$ Despite direct depiction of cortical bone breaks is difficult by MRI, this technique allows to visualise tiny signal changes linked to shifts in the water context of

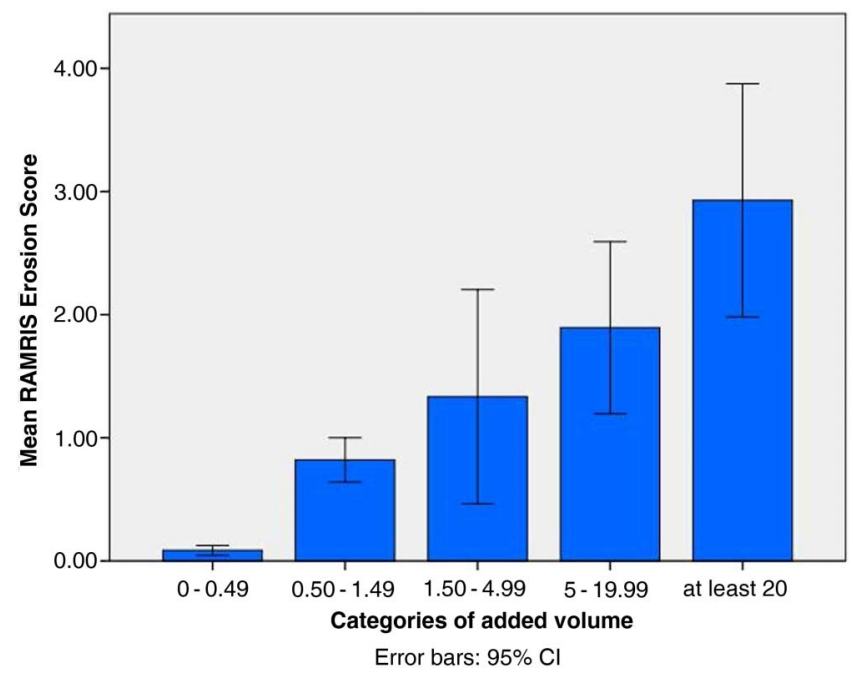

Figure 5 Mean RAMRIS Erosion Score for the respective categories of added volume. This figure is only reproduced in colour in the online version. the affected tissue, which, in case such changes are localised at sides, where normally bone is found, are highly indicative for erosions. ${ }^{23}$ Former studies have also shown that MRI lesions indicative for bone erosions are co-localised with cortical breaks in conventional CT examinations of joints. ${ }^{3}$ Dohn and collegues have performed an elegant study comparing the dimensions of individual erosions in the MRI and CT. In this study erosions detected in a standard clinical CT was compared with erosions detected in an MRI scanner with a rather low field strength of $0.6 \mathrm{~T}^{4}$ Dohn and colleagues found a rather high correlation between the size of individual erosions in the MRI and CT, which was slightly better, but in general comparable with our study. Still, discordant results were found, which were particularly due to the fact that some CT lesions escaped detection by MRI. In our study resolution of the CT scanner was far higher than in a standard clinical CT scanner showing a resolution of less than $200 \mu \mathrm{m}$ and a voxel size of less than $100 \mu \mathrm{m}$. Thus escape of even very small erosive lesions was virtually impossible by using such high-resolution three-dimensional CT scanning.

Our data strongly support the concept that MRI has an good performance to pick up bone erosions in patients with RA for several reasons: (i) MRI and $\mu C T$ lesions showed an virtually identical distribution pattern of bone erosions with preferential affection of the metacarpal heads as compared with the phalangeal bases, the second and third digits as compared with the fourth digit and the radial sides of the joints as compared with the ulnar sides. Similar distribution patterns have previously been reported for MRI studies and $\mu \mathrm{CT}$ studies in RA. ${ }^{2}{ }^{6}$ (ii) Moreover, overall numbers of bone erosions detected by either MRI or $\mu \mathrm{CT}$ were similar, showing no major misclassification of lesions. (iii) Finally, classification of extent of erosive damage by RAMRIS erosions scores correlated well with the true three-dimensional erosion size in the $\mu \mathrm{CT}$.

Only very small erosions of less than $10 \mathrm{~mm}^{3}$ occasionally escape detection by MRI. Interestingly, there was not a single erosion of more than $10 \mathrm{~mm}^{3}$ in size which was not detected by $\mu C T$ suggesting that MRI has indeed a very high sensitivity for depicting bone erosions ( $x_{\text {sens }>10}=1.00$; $\mathrm{x}_{\text {sens }}<10=0.76$ ). In this context it is noteworthy that very small erosions are not entirely specific for RA and can occasionally be found in healthy individuals, suggesting that their escape from MRI detection may not always have clinical relevance. Thus, MRI scans negative for bone erosions largely exclude major structural damage, whereas smaller lesions may escape detection. On the other hand, we detected erosive MRI changes without or with only very mild signs of erosions in the $\mu \mathrm{CT}$. Although the specificity of MRI to depict erosion appears to be high, MRI may overestimate the size of the true erosion by visualising the erosion itself but also the inflammatory tissue around such lesion. It can be speculated that such MRI changes may reflect preerosions, corresponding to inflammatory infiltrates with bone-resorbing osteoclast attached to the bone surface. Indeed, inflammatory bone marrow lesions have shown to predict bone erosions. ${ }^{9}$ Such inflammatory infiltrates attached to the bone surface have high water content and could reflect 'erosions' in the MRI. In fact, some of the very small lesions in the $\mu \mathrm{CT}$ were associated with rather large MRI 'erosions', which could indeed reflect early lesions with an active inflammatory infiltrate attached to the eroded and/or intact bone surface. Future longitudinal studies with sequential $\mu \mathrm{CT}$ measurements could support this hypothesis. 
In summary we show that MRI has high sensitivity and specificity for bone erosions. Only very small lesions occasionally escape detection by MRI and the RAMRIS scoring system of bone erosions excellently reflects the true three-dimensional size of erosions. These data thus support the use of MRI for detection and quantification of bone damage in RA.

Contributors AA was involved in patient recruitment, data acquisition and data analysis as well as in drafting the article. ME was involved in data analysis. SF was involved in patient recruitment, data acquisition and data analysis. GS was involved in data analysis drafting the article. The other authors were involved equally in data acquisition and analysis.

Funding This study was supported by the Deutsche Forschungsgemeinschaft (SPP1468-IMMUNOBONE), the Bundesministerium für Bildung und Forschung (BMBF; project ANCYLOSS) and the MASTERSWITCH project of the European Union and the IMl funded project BTCure.

Competing interests None.

Patient consent The study was performed in accordance with the Declaration of Helsinki. Approval was received from the local ethics committee and national radiation safety agency (Bundesamt für Strahlenschutz).

Ethics approval Local ethics committee.

Provenance and peer review Not commissioned; externally peer reviewed.

\section{REFERENCES}

1. Schett G, Firestein GS. Mr Outside and Mr Inside: classic and alternative views on the pathogenesis of rheumatoid arthritis. Ann Rheum Dis 2010;69:787-9.

2. Stach CM, Bauerle M, Englbrecht $\mathrm{M}$, et al. Periarticular bone structure in rheumatoid arthritis patients and healthy individuals assessed by high-resolution computed tomography. Arthritis Rheum 2010;62:330-9.

3. Perry D, Stewart N, Benton N, et al. Detection of erosions in the rheumatoid hand; a comparative study of multidetector computerized tomography versus magnetic resonance scanning. J Rheum 2005;32:256-67.

4. Dohn UM, Ejbjerg BJ, Hasselquist $\mathrm{M}$, et al. Rheumatoid arthritis bone erosion volumes on CT and MRI: reliability and correlations with erosion scores on CT, MRI and radiography. Ann Rheum Dis 2007;66:1388-92.

5. Ejbjerg BJ, Vestergaard A, Jacobsen $\mathrm{S}$, et al. Conventional radiography requires a MRl-estimated bone volume loss of $20 \%$ to $30 \%$ to allow certain detection of bone erosions in rheumatoid arthritis metacarpophalangeal joints. Arth Res Ther 2006;8:R59.

6. Tan AL, Tanner SF, Conaghan PG, et al. Role of metacarpophalangeal joint anatomic factors in the distribution of synovitis and bone erosion in early rheumatoid arthritis. Arthritis Rheum 2003:48:1214-22.

7. Conaghan PG, O'Connor P, McGonagle $\mathrm{D}$, et al. Elucidation of the relationship between synovitis and bone damage: a randomized magnetic resonance imaging study of individual joints in patients with early rheumatoid arthritis. Arthritis Rheum 2003;48:64-71.

8. McGonagle D, Conaghan PG, O'Connor $\mathrm{P}$, et al. The relationship between synovitis and bone changes in early untreated rheumatoid arthritis: a controlled magnetic resonance imaging study. Arthritis Rheum 1999;42:1706-11.

9. Hetland ML, Ejbjerg B, Horslev-Petersen K, et al. MRI bone oedema is the strongest predictor of subsequent radiographic progression in early rheumatoid arthritis. Results from a 2-year randomised controlled trial (CIMESTRA). Ann Rheum Dis 2009;68:384-90.

10. Scott DL, Smith C, Kingsley G. Joint damage and disability in rheumatoid arthritis: an updated systematic review. Clin Exp Rheumatol 2003;21:S20-7.

11. Welsing PM, van Gestel AM, Swinkels HL, et al. The relationship between disease activity, joint destruction, and functional capacity over the course of rheumatoid arthritis. Arthritis Rheum 2001:44:2009-17.

12. van der Heijde $\mathbf{D}$, Landewe $R$, van Vollenhoven $R$, et al. Level of radiographic damage and radiographic progression are determinants of physical function: a longitudinal analysis of the TEMPO trial. Ann Rheum Dis 2008;67:1267-70

13. Duer-Jensen A, Ejbjerg B, Albrecht-Beste E, et al. Does low-field dedicated extremity MRI (E-MRI) reliably detect bone erosions in rheumatoid arthritis? A comparison of two different E-MRI units and conventional radiography with high-resolution CT scanning. Ann Rheum Dis 2009;68:1296-302.

14. Ostergaard M, Pedersen SJ, Dohn UM. Imaging in rheumatoid arthritis-status and recent advances for magnetic resonance imaging, ultrasonography, computed tomography and conventional radiography. Best Prac Res Clin Rheum 2008;22:1019-44.

15. Ostergaard M, Edmonds J, McQueen F, et al. An introduction to the EULAR-OMERACT rheumatoid arthritis MRI reference image atlas. Ann Rheum Dis 2005;64(Suppl 1):i3-7.

16. Bird P, Conaghan P, Ejjjerg B, et al. The development of the EULAR-OMERACT rheumatoid arthritis MRI reference image atlas. Ann Rheum Dis 2005;64(Suppl 1):i8-10.

17. Conaghan $\mathbf{P}$, Bird $\mathrm{P}$, Ejbjerg $\mathrm{B}$, et al. The EULAR-OMERACT rheumatoid arthritis MRI reference image atlas: the metacarpophalangeal joints. Ann Rheum Dis 2005;64(Suppl 1):i11-21

18. McQueen $\mathbf{F}$, Ostergaard M, Peterfy, et al. Pitfalls in scoring MR images of rheumatoid arthritis wrist and metacarpophalangeal joints. Ann Rheum Dis 2005;64(Suppl 1):i48-55.

19. Hellebrandt FA, Duvall EN, Moore ML. The measurement of joint motion. Part 3. Phys Ther Rev 1949;29:195-205.

20. Boesen M, Ostergaard M, Cimmino MA, et al. MRI quantification of rheumatoid arthritis: current knowledge and future perspectives. Eur J Radiol 2009;71:189-96.

21. Jimenez-Boj E, Nobauer-Huhmann I, Hanslik-Schnabel B, et al. Bone erosions and bone marrow edema as defined by magnetic resonance imaging reflect- - true bone marrow inflammation in rheumatoid arthritis. Arthritis Rheum 2007:56:1118-24

22. Finzel S, Ohrndorf S, Englbrecht $\mathrm{M}$, et al. A detailed comparative study of high-resolution ultrasound and micro-computed tomography for detection of arthritic bone erosions. Arthritis Rheum 2011;63:1231-6.

23. McQueen FM, Ostendorf $B$. What is MRI bone oedema in rheumatoid arthritis and why does it matter? Arth Res Ther 2006;8:222. 


\section{ARD The structural basis of MRI bone erosions: an assessment by microCT}

Andreas Albrecht, Stephanie Finzel, Matthias Englbrecht, Jürgen Rech, Axel Hueber, Philipp Schlechtweg, Michael Uder and Georg Schett

Ann Rheum Dis 2013 72: 1351-1357 originally published online September 19, 2012

doi: 10.1136/annrheumdis-2012-201982

Updated information and services can be found at:

http://ard.bmj.com/content/72/8/1351

These include:

Supplementary Supplementary material can be found at:

Material http://ard.bmj.com/content/suppl/2012/09/18/annrheumdis-2012-2019 82.DC1.html

References This article cites 23 articles, 10 of which you can access for free at: http://ard.bmj.com/content/72/8/1351\#BIBL

Email alerting Receive free email alerts when new articles cite this article. Sign up in the service box at the top right corner of the online article.

ErrataAn erratum has been published regarding this article. Please see next page or:

http://ard.bmj.com/content/72/12/2056.full.pdf

Topic Articles on similar topics can be found in the following collections

Collections

Connective tissue disease (4234)

Degenerative joint disease (4621)

Immunology (including allergy) (5117)

Musculoskeletal syndromes (4930)

Rheumatoid arthritis (3245)

\section{Notes}

To request permissions go to:

http://group.bmj.com/group/rights-licensing/permissions

To order reprints go to:

http://journals.bmj.com/cgi/reprintform

To subscribe to BMJ go to:

http://group.bmj.com/subscribe/ 


\section{Correction}

Albrecht A, Finzel S, Englbrecht M, et al. The structural basis of MRI bone erosions: an assessment by microCT. Ann Rheum Dis 2013;72:1351-7. Figure 2 of this paper was mistakenly published with identical parts $\mathrm{A}$ and $\mathrm{B}$. The correct figure is below. In addition, as there are no separate parts '(A)' and '(B)' in figure 3, the labels '(A)' and '(B)' should not have been present in figure 3 legend. The corrected legend for figure 3 is: 'Correlation between the added erosion volumes (top: sum of marker erosion of ulnar and radial sides; middle: radial; bottom: ulnar) and the RAMRIS erosion score of the respective joint regions $(r=0.514$, $\mathrm{p}<0.001)$.'
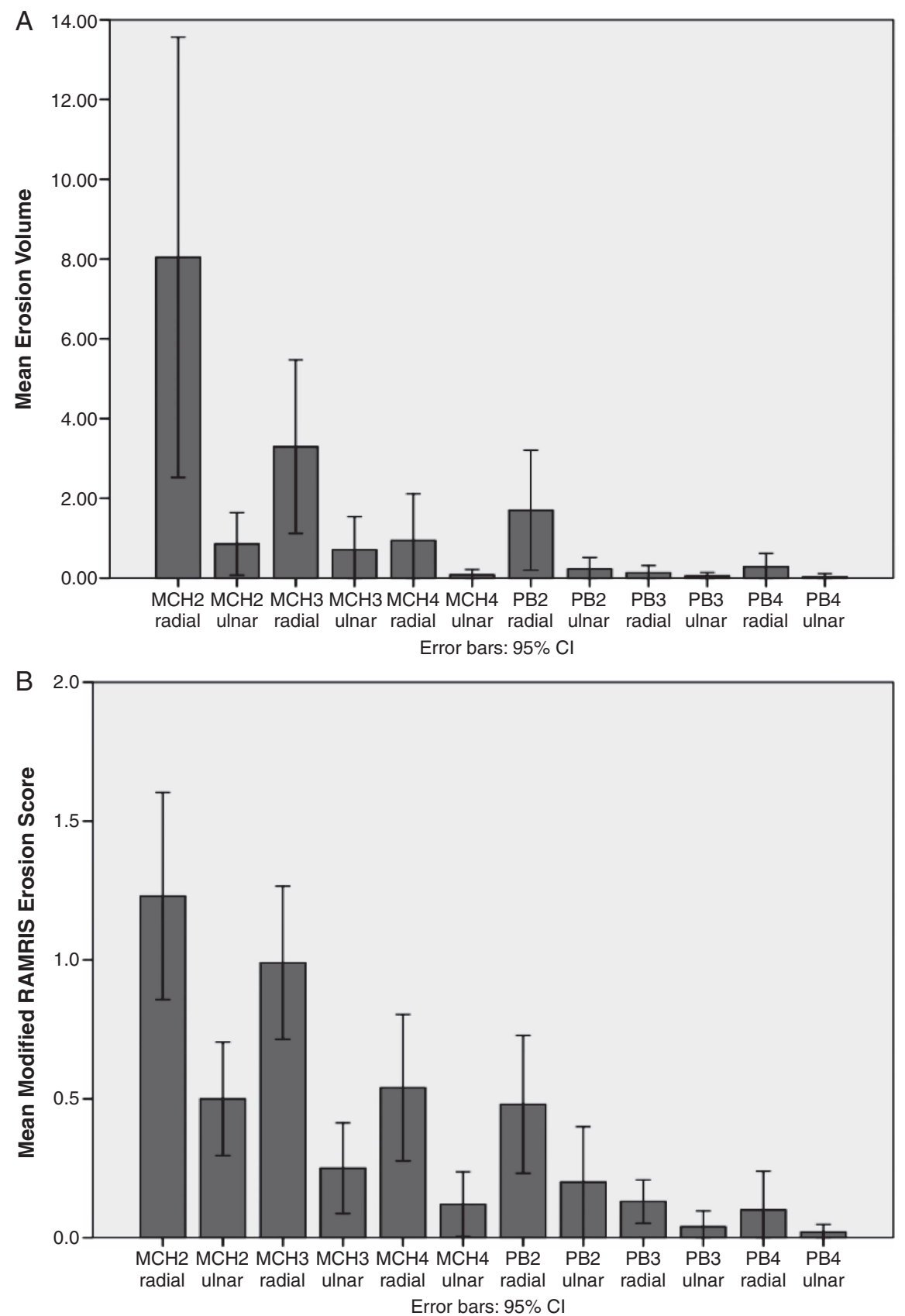

Figure 2 (A) Mean Erosion Volume of the examined joint regions for the $\mu$-CT scans; (B) Mean modified RAMRIS erosion score for the MRI scans. 